\title{
Prevalence and spectrum of LRRC10 mutations associated with idiopathic dilated cardiomyopathy
}

\author{
XIN-KAI QU ${ }^{1}$, FANG YUAN ${ }^{1}$, RUO-GU LI ${ }^{1}$, LEI XU ${ }^{1}$, WEI-FENG JING ${ }^{1}$, HUA LIU ${ }^{1}$, YING-JIA XU ${ }^{1}$,

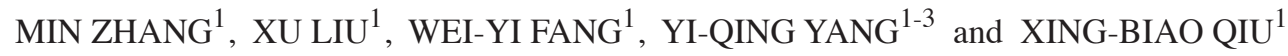 \\ ${ }^{1}$ Department of Cardiology; ${ }^{2}$ Cardiovascular Research Laboratory; ${ }^{3}$ Central Laboratory, \\ Shanghai Chest Hospital, Shanghai Jiao Tong University, Shanghai 200030, P.R. China
}

Received August 8, 2014; Accepted May 1, 2015

DOI: $10.3892 / \mathrm{mmr} .2015 .3843$

\begin{abstract}
Dilated cardiomyopathy (DCM) is the most common form of primary myocardial disease. It is the most common cause of chronic congestive heart failure and the most frequent reason for heart transplantation in young adults. There is increasing evidence demonstrating that genetic defects are involved in the pathogenesis of idiopathic DCM. Recent studies have shown that genetically defective LRRC10 predisposes animals to DCM. However, the association of LRRC10 with DCM in humans has not been reported. In the current study, the whole coding region and flanking splice junction sites of the LRRC10 gene were sequenced in 220 unrelated patients with idiopathic DCM. The available relatives of the index patients harboring identified mutations and 200 unrelated ethnically matched healthy individuals used as controls were also genotyped for $L R R C 10$. The functional effect of the LRRC10 mutations was analyzed in silico. As a result, two novel heterozygous LRRC10 mutations, p.L41V and p.L163I, were identified in two families with DCM, respectively, with a mutational prevalence of $\sim 0.91 \%$. Genetic analyses of the pedigrees showed that in each family, the mutation co-segregated with DCM was transmitted as an autosomal dominant trait with complete penetrance. The missense mutations were absent in 400 control chromosomes and the altered amino acids were completely conserved evolutionarily across various species. Functional analysis in silico indicated that the LRRC10 mutations were causative. This study firstly reports the association of LRRC10 mutations with enhanced susceptibility to DCM in humans, which provides novel insight into the molecular mechanism underpinning DCM,
\end{abstract}

Correspondence to: Dr Xing-Bio Qiu or Dr Yi-Qing Yang, Department of Cardiology, Shanghai Chest Hospital, Shanghai Jiao Tong University, 241 West Huaihai Road, Shanghai 200030, P.R. China

E-mail: qxingbiao@sina.cn

E-mail: yang99yang66@hotmail.com

Key words: dilated cardiomyopathy, genetics, LRRC10 and contributes to the development of novel prophylactic and therapeutic strategies for DCM.

\section{Introduction}

Dilated cardiomyopathy (DCM) is characterized by ventricular chamber enlargement and contractile dysfunction with normal ventricular wall thickness in the absence of associated conditions, such as coronary heart disease, hypertension and cardiac valve disease. It is the most common form of primary myocardial disease, affecting 1:2,500 (1). It is the most prevalent cause of chronic congestive heart failure and sudden cardiac death in individuals between the ages of 20 and 60 years-old, and is the most frequent reason for heart transplantation in humans $(1,2)$. A previous study identified that mortality or cardiac transplantation occurred in $26 \%$ of patients with childhood DCM within 1 year of diagnosis and $\sim 1 \%$ per year thereafter (3). Although certain acquired risk factors have been implicated in DCM, including viral myocarditis, myocardial infarction, arrhythmias and autoimmune disorders (4), in the majority of patients with DCM no secondary etiologies can be identified, this is defined as idiopathic DCM, among which $25-50 \%$ of DCM occur in at least two close relatives, hence termed familial DCM, and familial transmission of DCM has been observed to occur in an autosomal dominant, autosomal recessive or X-linked manner with variable expressivity and penetrance (1). Increasing evidence demonstrates that genetic defects are involved in the pathogenesis of idiopathic DCM, and mutations in $>50$ genes have been causally linked to idiopathic DCM (1,5-21). Nevertheless, these established DCM-associated genes are observed in less than a third of all cases and the genetic determinants underpinning DCM in an overwhelming majority of patients remain unclear (1,5-22).

Leucine rich repeat containing proteins (LRRCs), which contain multiple LRR motifs forming solenoid-shaped structures ideal for protein-protein interactions, have been involved in diverse cellular functions, including cell adhesion, signal transduction, ion channel expression, mechanical-stretch sensing, DNA repair and development (23-25). As a family member of LRRCs, LRRC10 is a cardiac-specific factor exclusively expressed in embryonic cardiomyocytes and in the hearts of adult zebrafish, mice and humans, exhibiting pivotal roles in cardiac development and function (26-28). In zebrafish, 
knockdown of LRRC10 using morpholinos resulted in severe cardiac morphogenic defects, including a cardiac looping failure accompanied by pericardial edema, and embryonic lethality between day 6 and 7 post fertilization. The LRRC10 morphants exhibited cardiac impairments, with decreased ejection fraction and cardiac output as well as reduced numbers of cardiomyocytes (29). In mice, targeted deletion of LRRC10 led to antenatal cardiac dysfunction and the development of DCM in early postnatal life (30). Furthermore, LRRC10 has been substantiated to interact physically with $\alpha$-actin and $\alpha$-actinin in the heart, forming a cytoskeletal complex, and mutations in $\alpha$-actin and $\alpha$-actinin have been causally linked to human DCM (30-32). These previous studies warrant the screening of LRRC10 as a novel DCM candidate gene in humans.

\section{Materials and methods}

Study subjects. To evaluate the prevalence and spectrum of LRRC10 mutations in patients with idiopathic DCM, a cohort of 220 genetically unrelated patients with idiopathic DCM was enrolled from the Han Chinese population, who were referred to Shanghai Chest Hospital between January $1^{\text {st }} 2011$ and December $31^{\text {st }} 2013$. The available relatives of the index patients harboring the identified $L R R C 10$ mutations were also included in this study. A total of 200 ethnically-matched unrelated healthy individuals were recruited as controls. All participants underwent a detailed medical history, physical examination, electrocardiogram, chest radiography, echocardiography and exercise tolerance test. Cardiac catheterization, coronary angiography and cardiac magnetic resonance imaging were applied only if there was a strong clinical indication. Medical records were also reviewed for deceased or unavailable relatives. Diagnosis of idiopathic DCM was made according to the criteria established by the World Health Organization/International Society and Federation of Cardiology Task Force on the Classification of Cardiomyopathy: A left ventricular enddiastolic diameter $>27 \mathrm{~mm} / \mathrm{m}^{2}$ and an ejection fraction $<40 \%$ or fractional shortening $<25 \%$ in the absence of abnormal loading conditions, coronary artery disease, congenital heart disease and other systemic diseases $(11,16,18,33)$. Subjects were excluded if they had poor echocardiographic image quality, or coexistent entities that may lead to cardiac systolic dysfunction, such as essential hypertension, coronary artery disease, and valvular heart disease. Familial DCM was defined when DCM occurred in two or more first-degree relatives. Peripheral venous blood samples from all the participants were collected. The clinical investigations were conducted with researchers blinded to the genotyping data. The study was conducted in accordance with the principles outlined in the Declaration of Helsinki of 1975 as revised in 2008. The study protocol was reviewed and approved by the local institutional ethics committee of Shanghai Chest Hospital, Shanghai Jiao Tong University (Shanghai, China). Prior to commencement of the study, all participants provided written informed consent for the use of their blood specimens for genetic analysis.

Genetic analysis of LRRC10. Genomic DNA was isolated from blood lymphocytes of each participant with Wizard Genomic DNA Purification kit (Promega Corporation, Madison, WI, USA). According to the referential genomic DNA sequence of the LRRC10 gene (GenBank accession no. NC_000012), the primers to amplify the entire coding region and flanking splice junction sites of $L R R C 10$ by polymerase chain reaction (PCR) were designed as shown in Table I. The coding exon and exon-intron boundaries of LRRC10 were PCR-sequenced in 220 unrelated patients with idiopathic DCM. When LRRC10 mutations were detected in index patients, the available relatives of the mutation carriers and 200 unrelated healthy controls were subsequently genotyped for $L R R C 10$. PCR was performed using HotStar Taq DNA Polymerase (Qiagen, Hilden, Germany) on a Verti Thermal Cycler (Applied Biosystems, Foster, CA, USA) with standard conditions and concentrations of reagents. Both strands of each PCR product were sequenced with a BigDye ${ }^{\circledR}$ Terminator v3.1 Cycle Sequencing kit (Applied Biosystems) under an ABI PRISM 3130 XL DNA analyzer (Applied Biosystems).

DNA sequences were analyzed with the DNA Sequencing Analysis Software v5.1 (Applied Biosystems). A sequence variation was verified by re-sequencing of an independent PCR-generated amplicon from the same subject. Additionally, for an identified variation, the public databases for human sequence variations, including single nucleotide polymorphism (SNP; http://www.ncbi.nlm.nih.gov/SNP) and human gene mutation (HGM; http://www.hgmd.org) databases, were analyzed to confirm its novelty.

Multiple alignments of LRRC10 amino acid sequences among species. Using the online MUSCLE program (version3.6; http://www.ncbi.nlm.nih.gov/homologene?cmd=Re trieve \&dopt=MultipleAlignment\&list_uids=17154), the human LRRC10 amino acid sequence was aligned with those of chimpanzee, monkey, dog, cattle, mouse, rat, fowl, zebrafish and frog.

Functional analysis of the LRRC10 sequence variations in silico. The disease-causing potential of $L R R C 10$ sequence variations were evaluated by MutationTaster (an online program at http://www.mutationtaster.org), which automatically gave a probability for the variation to be either a causative mutation or a benign polymorphism. Notably, the P-value used here is the probability of the correct prediction rather than the probability of error as used in t-test statistics (i.e., a value close to 1 indicates a high accuracy of the prediction).

Statistical analysis. Quantitative values are expressed as the mean \pm standard deviation. Continuous data were tested for normality of distribution and Student's unpaired t-test was used for the comparison of numeric variables between two groups. Comparison of the categorical variables between two groups was made using Pearson's $\chi^{2}$ test or Fisher's exact test when appropriate. A 2 -tailed $\mathrm{P}<0.05$ was considered to indicate a statistically significant difference.

\section{Results}

Baseline clinical characteristics of the study participants. A detailed evaluation of clinical data from 220 unrelated patients with idiopathic DCM and 200 control individuals was made. None of them had acquired risk factors for DCM. All the patients manifested with a progressive DCM phenotype without congenital cardiovascular defects. The control 
Table I. Primers to amplify the whole coding region and splice junction sites of the LRRC10 gene.

\begin{tabular}{llll}
\hline Exon & Forward primer (5' to 3') & Reverse primer (5' to 3') & Amplicon (bp) \\
\hline $1-\mathrm{a}$ & tag, gat, agg, ccc, cag, agc, ag & gga, gac, tca, gct, cac, aga, cc & 520 \\
$1-\mathrm{b}$ & gca, cct, tga, aac, agc, tct, gc & aga, aca, tgc, tgc, agt, tgg, gt & 600 \\
\hline
\end{tabular}

bp, base pairs.

Table II. Baseline clinical characteristics of the patients with DCM and control individuals.

\begin{tabular}{|c|c|c|c|}
\hline Variable & No. of patients $(n=220)$ & No. of controls $(n=200)$ & P-value \\
\hline Age (years) & $44.7 \pm 13.5$ & $45.1 \pm 12.9$ & 0.7569 \\
\hline Male (\%) & $104(47.3)$ & $95(47.5)$ & 1.0000 \\
\hline Family history of DCM (\%) & $62(28.2)$ & $0(0)$ & $<0.0001$ \\
\hline $\mathrm{SBP}(\mathrm{mmHg})$ & $115.2 \pm 14.8$ & $125.4 \pm 10.6$ & $<0.0001$ \\
\hline $\mathrm{DBP}(\mathrm{mmHg})$ & $77.0 \pm 8.5$ & $84.9 \pm 6.2$ & $<0.0001$ \\
\hline HR (beat per minute) & $86.7 \pm 10.0$ & $75.1 \pm 9.4$ & $<0.0001$ \\
\hline LVEDD (mm) & $69.3 \pm 7.5$ & $46.8 \pm 6.3$ & $<0.0001$ \\
\hline LVESD (mm) & $58.8 \pm 7.2$ & $34.5 \pm 5.6$ & $<0.0001$ \\
\hline $\operatorname{LVEF}(\%)$ & $39.3 \pm 8.2$ & $62.8 \pm 6.4$ & $<0.0001$ \\
\hline \multicolumn{4}{|l|}{ NYHA function class (\%) } \\
\hline I & $35(15.9)$ & NA & NA \\
\hline II & $47(21.4)$ & NA & NA \\
\hline III & $92(41.8)$ & NA & NA \\
\hline IV & $46(20.9)$ & NA & NA \\
\hline
\end{tabular}

DCM, dilated cardiomyopathy; SBP, systolic blood pressure; DBP, diastolic blood pressure; HR, heart rate; LVEDD, left ventricular end-diastolic diameter; LVESD, left ventricular end-systolic diameter; LVEF, left ventricular ejection fraction; NYHA, New York Heart Association; NA, not applicable or not available.

individuals had no evidence of structural cardiac diseases, and their echocardiographic results were normal. The baseline clinical characteristics of the study participants are summarized in Table II.

Identification of LRRC10 mutations. Using PCR-sequencing of the LRRC10 gene, two mutations were identified in 2 out of 220 unrelated patients with idiopathic DCM, respectively, with a mutational prevalence of $\sim 0.91 \%$. Specifically, a substitution of guanine for thymine in the first nucleotide of codon 41 (c.121T $>\mathrm{G})$, predicting the transition of leucine (L) into valine (V) at amino acid position 41 (p.L41V), was identified in the index patient from family 1 . A change of cytosine into adenine at nucleotide 487 (c.487C $>$ A), equivalent to a displacement of leucine at amino acid 163 by isoleucine (p.L163I), was detected in the proband from family 2. The sequence chromatograms showing the identified heterozygous LRRC10 mutations compared with their control sequences are displayed in Fig. 1. The missense mutations were neither identified in the 400 control chromosomes nor reported in the SNP or HGM databases. Genetic screening of the families revealed that in each family the mutation was present in all affected living family members, but absent in unaffected family members examined. Analysis of the pedigrees demonstrated that in each family the mutation co-segregated with DCM was transmitted in an autosomal dominant manner with complete penetrance (Fig. 2). Notably, during the most recent follow up, atrial fibrillation was recorded by standard 12-lead electrocardiogram in 2 patients with DCM (I-1 and II-1 from family 2), implying that DCM may be a key cause of atrial fibrillation. The phenotypic characteristics and status of LRRC10 mutations of the affected living family members are listed in Table III.

Alignment of multiple LRRC10 protein sequences across various species. As shown in Fig. 3, a cross-species alignment of LRRC10 protein sequences exhibited that the altered amino acids of p.L41 and p.L163 were evolutionarily conserved, indicating that these amino acids are functionally important.

Causative potential of the LRRC10 variations. The LRRC10 sequence variations of c.121T $>\mathrm{G}$ and c.487C $>\mathrm{A}$ were predicted by MutationTaster to be disease-causing mutations with P-values of 0.982216 for c.121T $>\mathrm{G}$ and 0.999719 for 
Table III. Phenotypic characteristics and status of LRRC10 mutations of the affected living pedigree members.

Subject Gender Age (years) Cardiac phenotype LVEDD (mm) LVESD (mm) LVEF (\%) LRRC10 mutation

\section{Family 1}

II-2 F $\quad$ F

III-1 M 32

57
32

DCM

78

64

67

67
55

22

$\mathrm{L} 41 \mathrm{~V}+/-$

Family 2

$\begin{array}{llllllll}\text { I-1 } & \text { M } & 61 & \text { DCM, AF } & 72 & 58 & 30 & \text { L163I +/- } \\ \text { II-1 } & \text { M } & 36 & \text { DCM, AF } & 80 & 69 & 25 & \text { L163I +/- } \\ \text { II-7 } & \text { F } & 29 & \text { DCM } & 62 & 50 & 36 & \text { L163I +/- }\end{array}$

F, female; M, male; DCM, dilated cardiomyopathy; AF, atrial fibrillation; LVEDD, left ventricular end-diastolic diameter; LVESD, left ventricular end-systolic diameter; LVEF, left ventricular ejection fraction; +/-, heterozygous mutation.

A

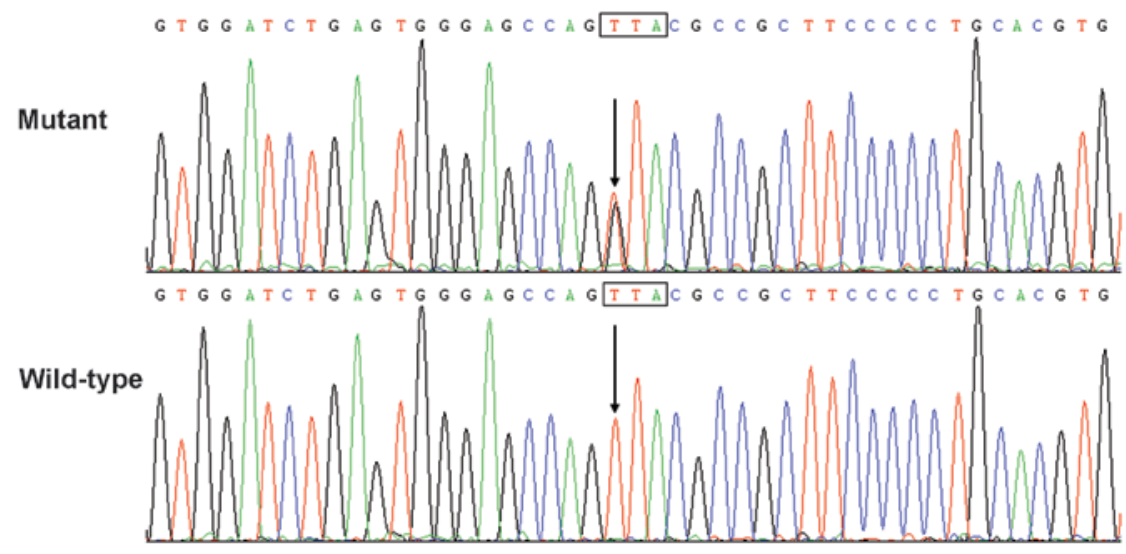

$\mathbf{B}$

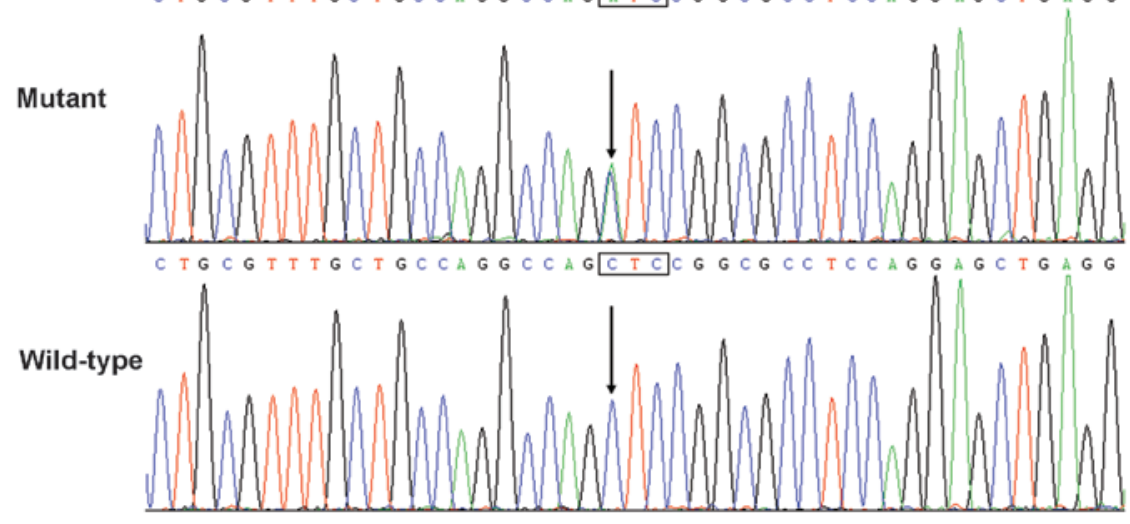

Figure 1. Sequence electropherograms showing the heterozygous LRRC10 mutations compared with their controls. The arrow points to the heterozygous nucleotides of $\mathrm{T} / \mathrm{G}$ (A) or C/A (B) in the patient with idiopathic dilated cardiomyopathy (mutant) or the homozygous nucleotides of T/T (A) or C/C (B) in the corresponding control individual (wild-type). The rectangle signifies the nucleotides comprising a codon of LRRC10.
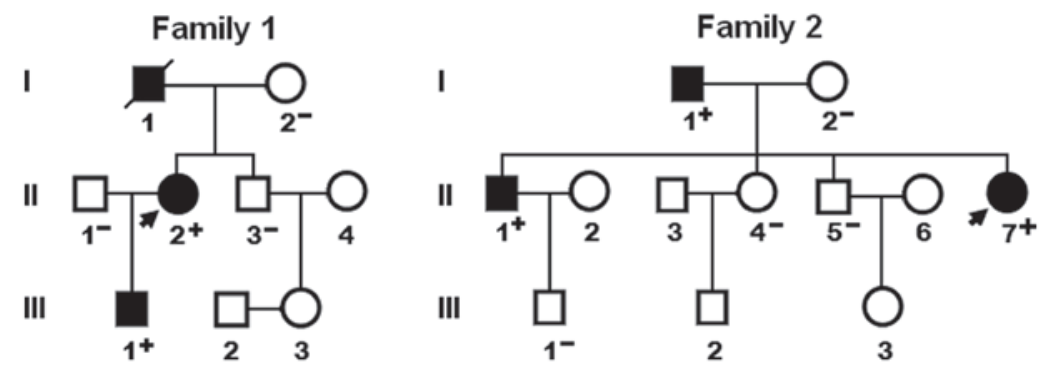

Figure 2. Pedigree structures of the families with idiopathic dilated cardiomyopathy. Families are designated as family 1 and family 2 , respectively. Family members are recognized by generations and numbers. Square, male; circle, female; symbol with a slash, deceased; closed symbol, affected; open symbol, unaffected; arrow, proband; '+', carrier of the heterozygous mutation; '-', non-carrier. 


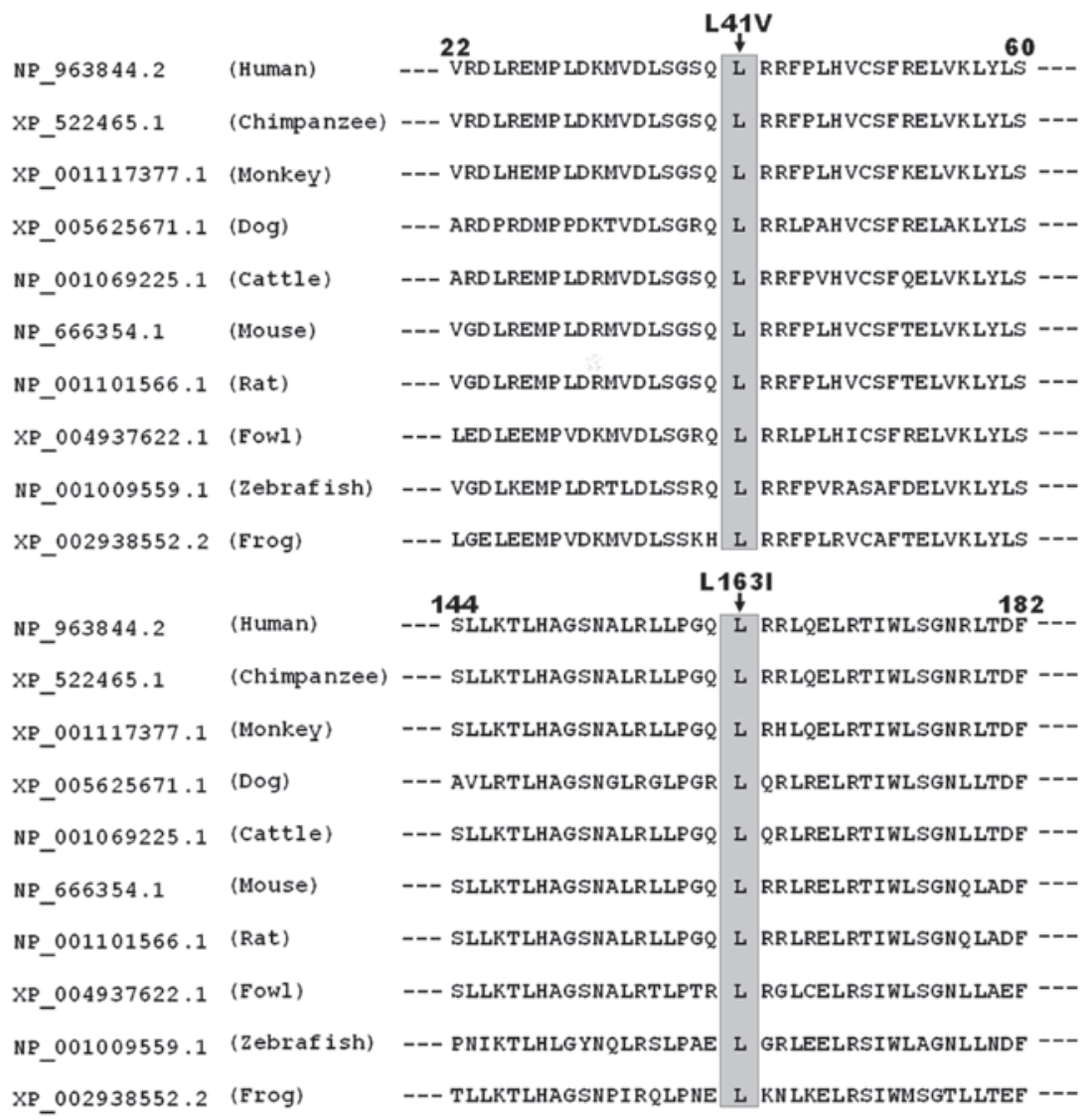

Figure 3. Multiple alignments of LRRC10 protein sequences across species. The altered amino acids of p.L41 and p.L163 are completely conserved evolutionarily among species.

c. $487 \mathrm{C}>\mathrm{A}$. No SNPs in the altered regions were found in the MutationTaster database.

\section{Discussion}

In this study, two novel heterozygous LRRC10 mutations, p.L41V and p.L163I, were identified in two families with idiopathic DCM, respectively. In each family the missense mutation co-segregated with DCM was inherited as an autosomal dominant trait with complete penetrance. The two mutations, which were absent in the 400 reference chromosomes from an ethnically-matched control population, altered the amino acids that were evolutionarily conserved. Functional analysis in silico indicated that the mutations were pathogenic. Hence, it is likely that LRRC10 mutations predispose these mutation carriers to DCM.

In humans, LRRC10 maps to chromosome 12q15, coding for a protein of 227 amino acids. LRRC10 is exclusively expressed in the precardiac region in early embryos and in the adult heart, and exhibits dynamic intracellular expression patterns in cardiomyocytes (26). Cardiomyocytes from embryos and newborns show diffuse cytoplasmic and nuclear distribution of LRRC10. By contrast, a striated expression pattern of LRRC10 is observed in adult cardiomyocytes, which colocalizes with the markers for the Z-disc, sarcoplasmic reticulum and transverse tubule. A further study by electron micrograph demonstrate that LRRC10 localizes predominantly to the diad region where the sarcoplasmic reticulum interacts with the transverse tubule, adjacent to the Z-disc (26). The Z-disc appears as a fine dense line forming sarcomere boundaries in striated muscles, where actin myofilaments are crosslinked primarily by $\alpha$-actinin (34). Therefore, the Z-disc is not only associated with lateral force transmission between sarcomeres, but also provides a mechanical link from the Z-disc myofilament to proteins in the peripheral subsarcolemmal costamere and eventually sarcolemma and extracellular matrix $(35,36)$. Moreover, the Z-disc is crucial in sensing and transducing signals in response to biomechanical stress in the cardiomyocyte $(35,37)$. Genetic deletion of several Z-disc and costameric proteins has been reported to cause DCM in mice, including Cypher (38), muscle LIM protein (39), enigma homologue protein (40), integrin-linked kinase (41) and vinculin (42). Furthermore, mutations in Cypher (43), muscle LIM protein (44), nexilin (45), myopalladin (46), integrin-linked kinase (47) and desmin (48) have been implicated in DCM in humans, indicating a key role for the dysfunction of Z-disc and costamere proteins in the pathogenesis of DCM. Given the fact that LRRC10 physically interacts with $\alpha$-actin and $\alpha$-actinin in the heart and directly interacts with all actin isoforms in vitro (30), mutant LRRC10 may confer increased vulnerability to DCM by disturbing the mechanical link between the Z-disc and the sarcolemma or cytoskeletal proteins.

The finding that genetically defective LRRC10 contributes to DCM may be partially ascribed to the abnormal development of the heart. As a cardiac-specific protein, LRRC10 is exclusively expressed in embryonic cardiomyocytes and the 
adult heart, exhibiting an essential role in cardiac development and function, possibly by interacting with other factors that are required for cardiac development and function (26-28). In zebra fish, the LRRC10-knockdown morphants manifested with a reduced ejection fraction and cardiac output, as well as a decreased quantity of cardiomyocytes. There was also deregulation of two cardiac genes, including an increase in atrial natriuretic factor, a hallmark for heart failure, and a decrease in cardiac myosin light chain 2, an essential protein for cardiac contractility (29). In LRRC10-null mice, diminished cardiac systolic performance occurred in utero, prior to ventricular dilation observed in young adults. Gene expression profiling of the LRRC10-deletious embryonic hearts revealed dysregulation of the actin cytoskeleton as an early defective molecular signal in the absence of LRRC10 (30). By contrast, microarray analyses of adult LRRC10-knockout hearts identified upregulation of oxidative phosphorylation and cardiac muscle contraction pathways during the progression of DCM (30). These experimental data demonstrate that LRRC10 is necessary for proper cardiac development and cardiac function. However, the exact mechanism by which the identified LRRC10 mutations result in or confer susceptibility to DCM remains to be elucidated by experiments in vivo and in vitro.

Notably, atrial fibrillation was documented in two DCM patients harboring an LRRC10 mutation. Furthermore, LRRC10 has been recognized as a transcriptional target of Nkx2.5 and GATA4 (49), and Nkx2.5 and GATA4 have been causally linked to DCM and atrial fibrillation $(11,16,18,50-59)$. These observational results imply that atrial fibrillation and DCM may share a common genetic origin.

In conclusion, the current study firstly provides genetic evidence supporting that functionally compromised LRRC10 contributes to the pathogenesis of DCM, and suggests potential implications of prenatal prophylaxis and gene-specific treatment of DCM.

\section{Acknowledgements}

The authors are thankful to the participants for their dedication to the study. This study was supported in part by grants from the National Natural Science Fund of China (grant no. 81270161), the Natural Science Fund of Shanghai, China (grant nos. 13ZR1438400 and 14ZR1438000) and the Key Program for Basic Research of Shanghai, China (grant no. 14JC1405500).

\section{References}

1. McNally EM, Golbus JR and Puckelwartz MJ: Genetic mutations and mechanisms in dilated cardiomyopathy. J Clin Invest 123 19-26, 2013.

2. Koutalas E, Kanoupakis E and Vardas P: Sudden cardiac death in non-ischemic dilated cardiomyopathy: a critical appraisal of existing and potential risk stratification tools. Int J Cardiol 167: 335-341, 2013.

3. Alexander PM, Daubeney PE, Nugent AW, Lee KJ, Turner C, Colan SD, Robertson T, Davis AM, Ramsay J, Justo R, Sholler GF, et al: National Australian childhood cardiomyopathy study: Long-term outcomes of dilated cardiomyopathy diagnosed during childhood: results from a national populationbased study of childhood cardiomyopathy. Circulation 128: 2039-2046, 2013.
4. Yoshikawa T: Contribution of acquired factors to the pathogenesis of dilated cardiomyopathy: The cause of dilated cardiomyopathy: Genetic or acquired? (Acquired-Side). Circ J 75: 1766-1773, 2011.

5. Wahbi K, Béhin A, Bécane HM, Leturcq F, Cossée M, Laforêt P, Stojkovic T, Carlier P, Toussaint M, Gaxotte V, Cluzel P, et al: Dilated cardiomyopathy in patients with mutations in anoctamin 5. Int J Cardiol 168: 76-79, 2013.

6. Ruppert V, Meyer T, Richter A, Maisch B and Pankuweit S: German competence network of heart failure: Identification of a missense mutation in the melusin-encoding ITGB1BP2 gene in a patient with dilated cardiomyopathy. Gene 512: 206-210, 2013.

7. Luo R, Li X, Fan X, Yuan W and Wu X: Association of tumor necrosis factor- $\alpha$ gene G-308A polymorphism with dilated cardiomyopathy: a meta-analysis. DNA Cell Biol 32: 130-137, 2013.

8. Meyer T, Ruppert V, Ackermann S, Richter A, Perrot A, Sperling SR, Posch MG, Maisch B and Pankuweit S: German competence network heart failure: Novel mutations in the sarcomeric protein myopalladin in patients with dilated cardiomyopathy. Eur J Hum Genet 21: 294-300, 2013.

9. Xi HL, Liu JF, Li L and Wan J: Relationship between dilated cardiomyopathy and the E23K and I337V polymorphisms in the Kir6.2 subunit of the KATP channel. Genet Mol Res 12: 4383-4392, 2013.

10. Pankuweit S, Ruppert V, Jónsdóttir T, Müller HH and Meyer T: German competence network of heart failure: The HLA class II allele DQB1 0309 is associated with dilated cardiomyopathy. Gene 531: 180-183, 2013.

11. Li RG, Li L, Qiu XB, Yuan F, Xu L, Li X, Xu YJ, Jiang WF, Jiang JQ, Liu X, Fang WY, et al: GATA4 loss-of-function mutation underlies familial dilated cardiomyopathy. Biochem Biophys Res Commun 439: 591-596, 2013.

12. Paavola J, Schliffke S, Rossetti S, Kuo IY, Yuan S, Sun Z, Harris PC, Torres VE and Ehrlich BE: Polycystin-2 mutations lead to impaired calcium cycling in the heart and predispose to dilated cardiomyopathy. J Mol Cell Cardiol 58: 199-208, 2013.

13. Wells QS, Becker JR, Su YR, Mosley JD, Weeke P, D'Aoust L, Ausborn NL, Ramirez AH, Pfotenhauer JP, Naftilan AJ, Markham L, et al: Whole exome sequencing identifies a causal RBM20 mutation in a large pedigree with familial dilated cardiomyopathy. Circ Cardiovasc Genet 6: 317-326, 2013.

14. Dhandapany PS, Razzaque MA, Muthusami U, Kunnoth S, Edwards JJ, Mulero-Navarro S, Riess I, Pardo S, Sheng J, Rani DS, Rani B, et al: RAF1 mutations in childhood-onset dilated cardiomyopathy. Nat Genet 46: 635-639, 2014.

15. Amin AS: SCN5A-related dilated cardiomyopathy: What do we know? Heart Rhythm 11: 1454-1455, 2014.

16. Li J, Liu WD, Yang ZL, Yuan F, Xu L, Li RG and Yang YQ: Prevalence and spectrum of GATA4 mutations associated with sporadic dilated cardiomyopathy. Gene 548: 174-181, 2014.

17. Petchey LK, Risebro CA, Vieira JM, Roberts T, Bryson JB, Greensmith L, Lythgoe MF and Riley PR: Loss of Prox 1 in striated muscle causes slow to fast skeletal muscle fiber conversion and dilated cardiomyopathy. Proc Natl Acad Sci USA 111: 9515-9520, 2014

18. Zhao L, Xu JH, Xu WJ, Yu H, Wang Q, Zheng HZ, Jiang WF, Jiang JF and Yang YQ: A novel GATA4 loss-of-function mutation responsible for familial dilated cardiomyopathy. Int J Mol Med 33: 654-660, 2014.

19. Zhang M, Chen J, Si D, Zheng Y, Jiao H, Feng Z, Hu Z and Duan R: Whole exome sequencing identifies a novel EMD mutation in a Chinese family with dilated cardiomyopathy. BMC Med Genet 15: 77, 2014.

20. Matsa LS, Sagurthi SR, Ananthapur V, Nalla S and Nallari P: Endothelin 1 gene as a modifier in dilated cardiomyopathy. Gene 548: 256-262, 2014.

21. Franaszczyk M, Bilinska ZT, Sobieszczańska-Małek M, Michalak E, Sleszycka J, Sioma A, Małek ŁA, Kaczmarska D, Walczak E, Włodarski P, Hutnik $Ł$, et al: The BAG3 gene variants in Polish patients with dilated cardiomyopathy: four novel mutations and a genotype-phenotype correlation. J Transl Med 12: 192, 2014.

22. Flack E and Kannankeril PJ: The genetics of dilated cardiomyopathy. Heart Rhythm 9: 397-398, 2012.

23. Kobe B and Deisenhofer J: Proteins with leucine-rich repeats. Curr Opin Struct Biol 5: 409-416, 1995.

24. Yan J and Aldrich RW: LRRC26 auxiliary protein allows BK channel activation at resting voltage without calcium. Nature 466: 513-516, 2010. 
25. Will RD, Eden M, Just S, Hansen A, Eder A, Frank D, Kuhn C, Seeger TS, Oehl U, Wiemann S, Korn B, et al: Myomasp/LRRC39, a heart- and muscle-specific protein, is a novel component of the sarcomeric M-band and is involved in stretch sensing. Circ Res 107: 1253-1264, 2010.

26. Kim KH, Kim TG, Micales BK, Lyons GE and Lee Y: Dynamic expression patterns of leucine-rich repeat containing protein 10 in the heart. Dev Dyn 236: 2225-2234, 2007.

27. Nakane T, Satoh T, Inada Y, Nakayama J, Itoh F and Chiba S: Molecular cloning and expression of HRLRRP, a novel heart-restricted leucine-rich repeat protein. Biochem Biophys Res Commun 314: 1086-1092, 2004.

28. Adameyko II, Mudry RE, Houston-Cummings NR, Veselov AP, Gregorio CC and Tevosian SG: Expression and regulation of mouse SERDIN1, a highly conserved cardiac-specific leucine-rich repeat protein. Dev Dyn 233: 540-552, 2005.

29. Kim KH, Antkiewicz DS, Yan L, Eliceiri KW, Heideman W, Peterson RE and Lee Y: Lrrc10 is required for early heart development and function in zebrafish. Dev Biol 308: 494-506, 2007.

30. Brody MJ, Hacker TA, Patel JR, Feng L, Sadoshima J, Tevosian SG, Balijepalli RC, Moss RL and Lee Y: Ablation of the cardiac-specific gene leucine-rich repeat containing 10 (Lrrc10) results in dilated cardiomyopathy. PLoS One 7: e51621, 2012.

31. Olson TM, Michels VV, Thibodeau SN, Tai YS and Keating MT: Actin mutations in dilated cardiomyopathy, a heritable form of heart failure. Science 280: 750-752, 1998

32. Mohapatra B, Jimenez S, Lin JH, Bowles KR, Coveler KJ, Marx JG, Chrisco MA, Murphy RT, Lurie PR, Schwartz RJ, Elliott PM, et al: Mutations in the muscle LIM protein and alpha-actinin-2 genes in dilated cardiomyopathy and endocardial fibroelastosis. Mol Genet Metab 80: 207-215, 2003.

33. Elliott P, O'Mahony C, Syrris P, Evans A, Rivera Sorensen C, Sheppard MN, Carr-White G, Pantazis A and McKenna WJ: Prevalence of desmosomal protein gene mutations in patients with dilated cardiomyopathy. Circ Cardiovasc Genet 3: 314-322, 2010 .

34. Luther PK: The vertebrate muscle Z-disc: sarcomere anchor for structure and signalling. J Muscle Res Cell Motil 30: 171-185, 2009.

35. Frank D and Frey N: Cardiac Z-disc signaling network. J Biol Chem 286: 9897-9904, 2011

36. Ervasti JM: Costameres: the Achilles' heel of Herculean muscle. J Biol Chem 278: 13591-13594, 2003.

37. Hoshijima M: Mechanical stress-strain sensors embedded in cardiac cytoskeleton: $\mathrm{Z}$ disk, titin and associated structures. Am J Physiol Heart Circ Physiol 290: H1313-H1325, 2006.

38. Zheng M, Cheng H, Li X, Zhang J, Cui L, Ouyang K, Han L, Zhao T, Gu Y, Dalton ND, Bang ML, et al: Cardiac-specific ablation of Cypher leads to a severe form of dilated cardiomyopathy with premature death. Hum Mol Genet 18: 701-713, 2009

39. Arber S, Hunter JJ, Ross J Jr, Hongo M, Sansig G, Borg J, Perriard JC, Chien KR and Caroni P: MLP-deficient mice exhibit a disruption of cardiac cytoarchitectural organization, dilated cardiomyopathy and heart failure. Cell 88: 393-403, 1997.

40. Cheng H, Kimura K, Peter AK, Cui L, Ouyang K, Shen T, Liu Y, Gu Y, Dalton ND, Evans SM, Knowlton KU, et al: Loss of enigma homolog protein results in dilated cardiomyopathy. Circ Res 107: 348-356, 2010

41. White DE, Coutu P, Shi YF, Tardif JC, Nattel S, St Arnaud R, Dedhar S and Muller WJ: Targeted ablation of ILK from the murine heart results in dilated cardiomyopathy and spontaneous heart failure. Genes Dev 20: 2355-2360, 2006.

42. Zemljic-Harpf AE, Miller JC, Henderson SA, Wright AT, Manso AM, Elsherif L, Dalton ND, Thor AK, Perkins GA, McCulloch AD and Ross RS: Cardiac-myocyte-specific excision of the vinculin gene disrupts cellular junctions, causing sudden death or dilated cardiomyopathy. Mol Cell Biol 27: 7522-7537, 2007.
43. Vatta M, Mohapatra B, Jimenez S, Sanchez X, Faulkner G, Perles Z, Sinagra G, Lin JH, Vu TM, Zhou Q, Bowles KR, et al: Mutations in Cypher/ZASP in patients with dilated cardiomyopathy and left ventricular non-compaction. J Am Coll Cardiol 42: 2014-2027, 2003.

44. Knöll R, Hoshijima M, Hoffman HM, Person V, Lorenzen-Schmidt I, Bang ML, Hayashi T, Shiga N, Yasukawa H, Schaper W, McKenna W, et al: The cardiac mechanical stretch sensor machinery involves a $\mathrm{Z}$ disc complex that is defective in a subset of human dilated cardiomyopathy. Cell 111: 943-955, 2002.

45. Hassel D, Dahme T, Erdmann J, Meder B, Huge A, Stoll M, Just S, Hess A, Ehlermann P, Weichenhan D, Grimmler M, et al: Nexilin mutations destabilize cardiac Z-disks and lead to dilated cardiomyopathy. Nat Med 15: 1281-1288, 2009.

46. Duboscq-Bidot L, Xu P, Charron P, Neyroud N, Dilanian G, Millaire A, Bors V, Komajda M and Villard E: Mutations in the Z-band protein myopalladin gene and idiopathic dilated cardiomyopathy. Cardiovasc Res 77: 118-125, 2008

47. Knöll R, Postel R, Wang J, Krätzner R, Hennecke G, Vacaru AM, Vakeel P, Schubert C, Murthy K, Rana BK, Kube D, et al: Lamininalpha4 and integrin-linked kinase mutations cause human cardiomyopathy via simultaneous defects in cardiomyocytes and endothelial cells. Circulation 116: 515-525, 2007.

48. Li D, Tapscoft T, Gonzalez O, Burch PE, Quiñones MA, Zoghbi WA, Hill R, Bachinski LL, Mann DL and Roberts R: Desmin mutation responsible for idiopathic dilated cardiomyopathy. Circulation 100: 461-464, 1999.

49. Brody MJ, Cho E, Mysliwiec MR, Kim TG, Carlson CD, Lee KH and Lee Y: Lrrc10 is a novel cardiac-specific target gene of Nkx2-5 and GATA4. J Mol Cell Cardiol 62: 237-246, 2013.

50. Pashmforoush M,Lu JT, Chen H,Amand TS,Kondo R, Pradervand S, Evans SM, Clark B, Feramisco JR, Giles W, Ho SY, et al: Nkx2-5 pathways and congenital heart disease; loss of ventricular myocyte lineage specification leads to progressive cardiomyopathy and complete heart block. Cell 117: 373-386, 2004.

51. Costa MW, Guo G, Wolstein O, Vale M, Castro ML, Wang L, Otway R, Riek P, Cochrane N, Furtado M, Semsarian C, et al: Functional characterization of a novel mutation in NKX2-5 associated with congenital heart disease and adult-onset cardiomyopathy. Circ Cardiovasc Genet 6: 238-247, 2013.

52. Gutierrez-Roelens I, De Roy L, Ovaert C, Sluysmans T, Devriendt K, Brunner HG and Vikkula M: A novel CSX/NKX2-5 mutation causes autosomal-dominant AV block: are atrial fibrillation and syncopes part of the phenotype? Eur J Hum Genet 14: 1313-1316, 2006

53. Huang RT, Xue S, Xu YJ, Zhou M and Yang YQ: A novel NKX2.5 loss-of-function mutation responsible for familial atrial fibrillation. Int J Mol Med 31: 1119-1126, 2013.

54. Xie WH, Chang C, Xu YJ, Li RG, Qu XK, Fang WY, Liu X and Yang YQ: Prevalence and spectrum of Nkx2.5 mutations associated with idiopathic atrial fibrillation. Clinics (Sao Paulo) 68: 777-784, 2013.

55. Yu H, Xu JH, Song HM, Zhao L, Xu WJ, Wang J, Li RG, Xu L, Jiang WF, Qiu XB, Jiang JQ, et al: Mutational spectrum of the NKX2-5 gene in patients with lone atrial fibrillation. Int J Med Sci 11: 554-563, 2014

56. Posch MG, Boldt LH, Polotzki M, Richter S, Rolf S, Perrot A, Dietz R, Ozcelik C and Haverkamp W: Mutations in the cardiac transcription factor GATA4 in patients with lone atrial fibrillation. Eur J Med Genet 53: 201-203, 2010.

57. Yang YQ, Wang MY, Zhang XL, Tan HW, Shi HF, Jiang WF, Wang XH, Fang WY and Liu X: GATA4 loss-of-function mutations in familial atrial fibrillation. Clin Chim Acta 412: $1825-1830,2011$

58. Jiang JQ, Shen FF, Fang WY, Liu X and Yang YQ: Novel GATA4 mutations in lone atrial fibrillation. Int J Mol Med 28: 1025-1032, 2011.

59. Wang J, Sun YM and Yang YQ: Mutation spectrum of the GATA4 gene in patients with idiopathic atrial fibrillation. Mol Biol Rep 39: 8127-8135, 2012. 